\section{Isolation of potential fluorescent pseudomonads from Kuini (Mangifera odorata) planted soil and their potential as biofertilizer}

\author{
Seng Heng Jeffrey Lim, \\ Nur Samahah Mohd Zainual
}

Green Technology Program,

Agrobiodiversity and Environment

Research Center, Malaysian

Agricultural Research and Development

Institute, Persiaran MARDI-UPM,

Serdang, Selangor, Malaysia

\begin{abstract}
Pseudomonas sp. are known to be good Plant Growth Promoting Rhizobacteria (PGPR). In this study, Pseudomonas sp. were isolated from soil planted with kuini (Mangifera odorata) using soil dilution method and spread onto King's B media. Five isolates of Pseudomonas sp. were observed to give promising results in the phytohormone and antimicrobial test conducted. These isolates are Pseudomonas sp. isolate K24pf, K29pf, K32pf, K33pf and $\mathrm{K} 37 \mathrm{pf}$. From the 5 potential isolates, Pseudomonas sp. isolate K29pf was chosen because it showed potential activity in producing marked amounts of Indole-3-Acetic Acid and gibberellic acid. Pseudomonas sp. isolate $\mathrm{K} 29 \mathrm{pf}$ also produced antimicrobial activities towards Ralstonia solanacearum, Erwinia caratovora, Erwinia mallotivora and Colletotrichum gloeosporioides. Seed germination test showed that Pseudomonas $\mathrm{sp}$. isolate $\mathrm{K} 29 \mathrm{pf}$ was able to promote approximately $90 \%$ growth of Brassica chinensis seeds. Pot trial conducted showed that Treatment 3 (+OF+PGPR) was able to increase Brassica chinensis root by $36.5 \%$ and $28.4 \%$ of its biomass compared to treatment using Treatment 1 (+OF).
\end{abstract}

\section{Introduction}

Soil is the most complex and heterogeneous of natural system composed of solid, liquid and gaseous phase. Soil is the habitat for many beneficial and pathogenic microorganisms. Bacteria inhabiting the rhizosphere can influence plant growth by producing certain bioactive compounds beneficial to the plants such as phytohormones and antibiotics. ${ }^{1,2}$ These bacterial groups are known as Plant Growth
Promoting Rhizobacteria (PGPR). ${ }^{3}$

Plant Growth Promoting Rhizobacteria include the species in the genera of Bacillus, Pseudomonas, Azotobacter and Rhizobium. An effective PGPR should have these characteristics; ability of root colonization, phytostimulator and biocontrol agent against certain phytopathogens. ${ }^{3}$ Pseudomonas sp. has been known as one of the most important members of PGPRs that showed all these three characteristics of PGPR. ${ }^{3}$ Wahyudi et al. ${ }^{4}$ and Vasanthakumar and McManus, ${ }^{5}$ showed that some Pseudomonas sp. such as Pseudomonas gingeri and Peudomonas alcaligenes has the ability to produce Indole Acetic Acid (IAA), which is important for the root growth. ${ }^{5}$ Studies by Pandey and Desai ${ }^{6}$ showed that Pseudomonas sp. also has the ability to produce gibberellic acid which is important to promote the growth and of yield of plants. Dey et al. ${ }^{7}$ showed that Pseudomonas sp. isolated were effective to produce phyto-activities toward phytopathogens such as Aspergillus niger and $A$. flavus. In another study, Wahyudi et al. ${ }^{4}$ showed that Pseudomonas sp. isolated form rhizosphere of soybean field have the ability to inhibit the growth of Fusarium oxysporum, Rhizoctonia solani and Sclerotium rolfsii, the causal agent of root rot disease.

In this study, our objectives are to isolate pseudomonas from kuini (Mangifera ordorata) planted soil, characterize their potential bioactivities and analyzed their efficacy on a pot trial. As this is the pioneer work regarding isolation of PGPR from Mangifera ordorata in Malaysia, we will focus on the best known PGPR which is the Pseudomonas sp.

\section{Materials and Methods}

\section{Isolation of soil microbes}

Pseudomonas sp. were isolated from kuini (Mangifera ordorata) planted soil collected from MARDI Sintok, Kedah, Malaysia (Latitude: 6²9'6.98” Longitude: $\left.100^{\circ} 29^{\prime} 2.27^{\prime \prime}\right)$. Soil samples were collected at the depth of $15 \mathrm{~cm}$ from the rhizosphere. These soils were from the soil type of Siri Napai a type of laterite soil. The collected soil samples were kept in ice box when transporting back to MARDI Headquater located at Serdang, Selangor, Malaysia. The samples were crushed into smaller pieces and were processed by diluting $10 \mathrm{~g}$ of the soil sample in $100 \mathrm{ml}$ of sterile distilled water $\left(\mathrm{sH}_{2} \mathrm{O}\right)$. The soil suspension was vigorously agitated at $200 \mathrm{rpm}$ for $1 \mathrm{~h}$. After 1 h, $150 \mu \mathrm{l}$ of the soil suspension was pipetted onto King's B agar. ${ }^{8}$ Agar plates were then
Correspondence: Seng Heng Jeffrey Lim, Green Technology Program, Agrobiodiversity and Environment Research Center, Malaysian Agricultural Research and Development Institute, Persiaran MARDI-UPM, 43400 Serdang, Selangor, Malaysia.

Tel.: +603.8953.7243 - Fax: +603.8953.7200 E-mail: shlim@mardi.gov.my

Key words: Plant Growth Promoting Rhizobacteria; Fluorescent pseudomonads; Biofertilizer; Mangifera odorata.

Acknowledgements: the authors would like to thank Ms. Siti Noor Ashikin and Dr. Razean Haireen for helping out with the collection of soil samples and also everybody that has contributed directly or indirectly in this project.

Contributions: JLSH: sample collection, Polymerase Chain Reaction of bacteria, data analysis, pot trial and writing of article; NS: bacterial isolation, fluorescent pseudomonads characterizations, pot trial and co-writer of paper.

Conflict of interest: the authors declare no potential conflict of interest.

Funding: this work was supported by Malaysian government under the 11 th Malaysian Plan (RMK11-PGB-407).

Received for publication: 23 August 2018.

Revision received: 13 February 2019.

Accepted for publication: 24 February 2019.

This work is licensed under a Creative Commons Attribution NonCommercial 4.0 License (CC BY-NC 4.0).

(C) Copyright S.H. Jeffrey Lim and

N.S. Mohd Zainual, 2019

Licensee PAGEPress, Italy

Microbiology Research 2019; 10:7844

doi:10.4081/mr.2019.7844

incubated at $28 \pm 2^{\circ} \mathrm{C}$ for $48 \mathrm{~h}$. After that, the agar plates were exposed to UV light at $365 \mathrm{~nm}$ for selection of any fluorescent colonies. The emerging colonies were selected and streaked onto a fresh new agar plate for further usage.

\section{Screening of Indole-3-Acetic Acid}

For Indole-3-Acetic Acid (IAA) estimation, method used by Iqbal and Hasnain, ${ }^{9}$ was followed with a little modification. Fluorescent pseudomonads isolated were incubated at $30 \pm 2^{\circ} \mathrm{C}$ for $48 \mathrm{hrs}$. The density of the culture broths were then adjusted to $10^{6} \mathrm{cfu} / \mathrm{mL}$ for each test isolates. Two mililiter of the culture broth was pipetted into a new Eppendorf tube and centrifuged at $10,000 \mathrm{rpm}$ for $30 \mathrm{~min}$. After centrifugation, $1 \mathrm{ml}$ of the supernatant was mixed with $2 \mathrm{~mL}$ of Salkowski's reagent in a test tube 
Table 1. Treatment used in pot trial of Brassica chinensis var parachinens.

\begin{tabular}{lll} 
Treatment & Representation & Amount added \\
Treatment 1: Baba organic fertilizer (4:2:6) & + OF & $3 \mathrm{~g} /$ application \\
Treatment 2: Pseudomonas sp. strain K29pf & + +PGPR & $50 \mathrm{ml} / \mathrm{application}$ \\
\hline Treatment 3: Baba organic fertilizer (4:2:6) + Pseudomonas sp. strain K29pf & + OF+PGPR & $3 \mathrm{~g}+50 \mathrm{ml} / \mathrm{application}$ \\
Treatment 4: No fertilizer added & Control & Nil \\
\hline
\end{tabular}

PGPR, plant growth promoting rhizobacteria.

and allowed to stand in dark for $30 \mathrm{~min}$. Development of pink color indicated IAA production and the amount of IAA was measured using Nanodrop spectrophotometer at wavelength of $530 \mathrm{~nm}$. A standard curve was constructed using synthetic IAA (Sigma, Seelze, Germany) with purity of $99.3 \%$ to determine the amount of IAA secreted by each fluorescent pseudomonads.

\section{Screening of gibberellic acid}

Screening of gibberellic acid $\left(\mathrm{GA}_{3}\right)$ producing fluorescent pseudomonad was done according to method proposed by Panday and Desai. ${ }^{6}$ Standard curve was constructed using synthetic $\mathrm{GA}_{3}$ (Sigma) and was measured at $254 \mathrm{~nm}$ using Nanodrop spectrophotometer.

\section{Screening for nitrogen fixer and phosphate solubilizer activity}

For the screening of nitrogen fixer from fluorescent pseudomonads, Burk's Nitrogen free medium was used ( $10.0 \mathrm{~g}$ glucose, 0.41 $\mathrm{g} \mathrm{KH}_{2} \mathrm{PO}_{4}, 0.52 \mathrm{~g} \mathrm{~K}_{2} \mathrm{HPO}_{4}, 0.05 \mathrm{~g} \mathrm{Na}_{2} \mathrm{SO}_{4}$, $0.2 \mathrm{~g} \mathrm{CaCl}_{2}, 0.1 \mathrm{~g} \mathrm{MgSO}_{4} 7 \mathrm{H} 2 \mathrm{O}, 0.005 \mathrm{~g}$ $\mathrm{FeSO}_{4} 7 \mathrm{H}_{2} \mathrm{O}, 0.0025 \mathrm{~g} \mathrm{Na}_{2} \mathrm{MoO}_{4} 2 \mathrm{H}_{2} \mathrm{O}$ and $15 \mathrm{~g}$ agar-agar in $1 \mathrm{~L}$ of $\left.\mathrm{sdH}_{2} \mathrm{O}\right) .{ }^{10}$ The $\mathrm{pH}$ of the medium was adjusted to $7.0 \pm 0.2$ prior autoclaving at $121^{\circ} \mathrm{C}$ for $15 \mathrm{~min}$. The fluorescent pseudomonads were screened for their phosphate solubilizing ability using Pikovskaya's agar (10.0 g glucose, $5 \mathrm{~g}$ $\mathrm{Ca}_{3}\left(\mathrm{PO}_{4}\right)_{2}, \quad 0.5 \mathrm{~g}$ yeast extract, $0.5 \mathrm{~g}$ $\left(\mathrm{NH}_{4}\right)_{2} \mathrm{SO}_{4} ; 0.2 \mathrm{~g} \mathrm{NaCl} ; 0.2 \mathrm{~g} \mathrm{KCl} ; 0.1 \mathrm{~g}$ $\mathrm{MgSO}_{4}, 0.005 \mathrm{~g} \mathrm{FeSO}_{4} 7 \mathrm{H}_{2} \mathrm{O} \mathrm{MnSO} 4 \mathrm{H} 2 \mathrm{O}$ $0.001 \mathrm{~g}$ and $15.0 \mathrm{~g}$ agar-agar in $1 \mathrm{~L}$ of $\left.\mathrm{sdH}_{2} \mathrm{O}\right) .{ }^{11}$ The $\mathrm{pH}$ was adjusted to $7.0 \pm 0.2$ autoclaving at $121^{\circ} \mathrm{C}$ for $15 \mathrm{~min}$. Isolates of fluorescent pseudomonads were then grown on the each of the plates in triplicates and halo zones formed indicate the positive activity for the tested bacteria.

\section{Screening of antimicrobial activities}

Screening of anitimicrobial activities were conducted based on the culture overlay method. The phyto-pathogens used were Ralstonia solanacearum (MMCC10019), Erwinia caratovora (MMCC10018), Erwinia mallotivora (MMCC10032), Colletotrichum capsicii (MMCC20012) and Colletotrichum gloeosporioides (MMCC20013). Anti-bacterial test was

Table 2. Arrangement of the treatment in Randomized Complete Block Design.

\begin{tabular}{ccccc} 
R1 & R2 & R3 & R4 & R5 \\
$(+\mathrm{OF})$ & Control & $(+\mathrm{OF}+\mathrm{PGPR})$ & $(+\mathrm{PGPR})$ & $(+\mathrm{PGPR})$ \\
$(+\mathrm{PGPR})$ & $(+\mathrm{OF})$ & Control & $(+\mathrm{OF}+\mathrm{PGPR})$ & $(+\mathrm{OF})$ \\
\hline$(+\mathrm{OF}+\mathrm{PGPR})$ & $(+\mathrm{PGPR})$ & $(+\mathrm{OF})$ & Control & $(+\mathrm{OF}+\mathrm{PGPR})$ \\
Control & $(+\mathrm{OF}+\mathrm{PGPR})$ & $(+\mathrm{PGPR})$ & $(+\mathrm{OF})$ & Control \\
\hline
\end{tabular}

conducted by lawning the test pathogenic bacteria onto the media plate and the agar block with pseudomonas was overlayed on top of the phytopathogens. For anti-fungal test, a dual cultures agar test was performed, where the pathogenic fungi was inoculated at the center of the agar plate and flanked by tested fluorescent pseudomonads on left and right side of the agar. Clear zone produced indicates the ability to secrete antimicrobial compound against the tested pathogens. Antimicrobial activity was evaluated after $24 \mathrm{~h}$ of incubating and the clear zones were rated using the rating scheme suggested by Baniasadi et al. ${ }^{12}$ from the modification of rating by Lee and Hwang, ${ }^{13}$ whereby; $0-4 \mathrm{~mm}=$ no inhibition, 5-9 $\mathrm{mm}=$ weak inhibition, $10-19 \mathrm{~mm}=$ moderate inhibition and $\geq 20 \mathrm{~mm}=$ strong inhibition.

\section{Identification of beneficial microbes}

Isolation of DNA was conducted using Qiagen DNeasy DNA extraction protocol as suggested by the manufacturer. PCR parameters and conditions used for this study followed the optimization made by Jeffrey ${ }^{14}$ with the modification on the primers used. The 16S rRNA gene region was amplified using universal primers F8 (AGA GTT TGA TCM TGG CTC) and rP2 (ACG GCT ACC TTG TTA CGA CTT) ${ }^{15}$ PCR products obtained were subjected to purification using Vivantis GF-1 Gel DNA recovery kit following the protocol provided by the manufacturer. The purified PCR products were sent for sequencing at First Base Laboratories Sdn. Bhd., Selangor. Results obtained from the sequencing were then compared with the databases from National Center for Biotechnology Information.

\section{Germination test}

Germination test was conducted using 20 seeds of Brassica chinensis var parachinens for each treatment. Mean of 20 seeds weighted at $0.0464 \pm 0.002 \mathrm{~g}$. The seeds were pre-soaked with $10 \mathrm{ml}$ of selected fluorescent pseudomonads culture broths for 30 mins while control seeds were soaked with $10 \mathrm{ml}$ of water for the same duration. After $30 \mathrm{~min}$, seeds from each treatment were dried in laminar flow for $2 \mathrm{hrs}$ before being transferred onto filter paper placed in the $90 \times 15 \mathrm{~mm}$ petri dishes. The filter papers were then wetted with $5 \mathrm{ml}$ of fluorescent pseudomonads broths while sterile distilled water of $5 \mathrm{ml}$ was used as control for 5 days. Number of seed germinated in 5 days were counted and represented as percentage of germination. Tests were conducted in room temperature $28 \pm 2^{\circ} \mathrm{C}$ and all tests were conducted in triplicates.

\section{Pot trial}

Soil used for the planting of Brassica chinensis var parachinens was cocoa peat obtained from local market. Three seeds of Brassica chinensis var parachinens were planted in each pot. A total $50 \mathrm{ml}$ broth containing Pseudonomas sp. strain K29pf with the concentration of $10^{6}$ were inoculated onto the soil for each pot in treatment 2 and 3 , while $3 g$ of organic fertilizer was added around the plant in each pot in treatment 1 and 3 (Table 1). No artificial lighting were provided to induce the plant growth. The plants were watered manually every morning and evening during the experiment. Temperature was recorded twice a day in the morning (around time 0900) and in the evening (around time 1700). The treatments used are shown in Table 1.

Treatments were applied twice throughout the experiment on $1^{\text {st }}$ and $15^{\text {th }}$ day after planting. B. chinensis var parachinens was harvested on day 30 after planting. The fresh weight, dry weight and root length of the plants for each treatment were recorded. The tests were conducted with 5 replicates for each treatment and in a randomized complete block design method (Table 2). 
Fresh weight of the plants were taken immediately after harvesting. While the dry weight of the plants were taken after oven drying at $55^{\circ} \mathrm{C}$ overnight. The dried plants were place in a ziplock bag once it is removed from the oven to prevent the plant from contacting with the surrounding moisture. The dry weight was determine by subtracting the weight of the dry plant with the ziplock bag with the emptied ziplock bag.

Dry weight $(\mathrm{g})=$ (weight of dried plant in ziplock bag) - (weight of emptied ziplock bag).

\section{Statistical data analysis}

All data for fresh plant weight, dry plant weight and root elongation was done using one way analysis of variance was done using SAS 9.3 software. The Tukey's honest significant difference at $\mathrm{P}=0.05$ was used to determine the significance among the samples.

\section{Results \\ Isolation of soil fluorescent pseudomonads and screening of IAA and $\mathbf{G A}_{3}$ activities}

A total of 25 Pseudomonas sp. was isolated soil of kuini plot from MARDI Sintok. The average colony forming unit per gram soil $(\mathrm{cfu} / \mathrm{g})$ for Pseudomonas sp. isolated was $7.3 \times 10^{5}$. We observed that $100 \%$ of the fluorescent pseudomonads presented the ability to produce IAA but only $20 \%$ showed the ability to produce $\mathrm{GA}_{3}$. The results are shown in Table 3.

Screening of nitrogen fixation, phosphate solubilization, antimicrobial activities and identification of fluorescent pseudomonads

Secretion of bioactivities by microbes was known to be an important characteristic for the microbes to stay viable in their ecosystem. From the total of 25 fluorescent pseudomonads isolated, $60 \%$ of the Pseudomonas sp. showed antimicrobial activity towards Ralstonia solanacearum (MMCC10019), 20\% for Erwinia caratovora (MMCC10018), 18\% towards Erwinia mallotivora (MMCC10032), 4\% Colletotrichum capsicii (MMCC20012) and $8 \%$ for Colletotrichum gloeosporioides (MMCC20013). Antimicrobial activity of selected fluorescent pseudomonads were tabulated in Table 3.

Screening for phosphate solubilizing and nitrogen fixation ability of 25 isolates of fluorescent pseudomonads isolated showed that only $8 \%$ of the fluorescent pseudomonads isolates gave positive reaction to the phosphate solubilizing media used, while no nitrogen fixation activities was observed for all 25 isolates of fluorescent pseudomonads (Table 3 ). The 5 poten-

Table 3. Phytohormone, antimicrobial and enzymatic activities produced by 25 isolates of Pseudomonas sp. isolated form kuini soil.

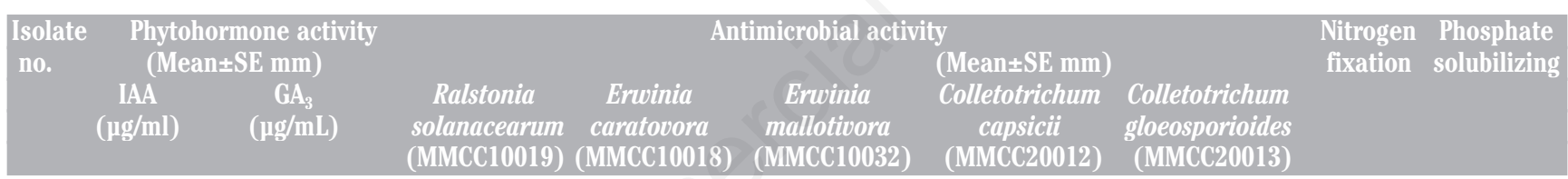

\begin{tabular}{|c|c|c|c|c|c|c|c|c|c|}
\hline Klpf & $1.24 \pm 0.03$ & - & $8.40 \pm 0.53$ & $6.40 \pm 0.27$ & - & - & - & - & - \\
\hline $\mathrm{K} 2 \mathrm{pf}$ & $0.53 \pm 0.10$ & - & $10.20 \pm 0.43$ & - & - & - & - & - & - \\
\hline K5pf & $0.82 \pm 0.03$ & - & - & - & - & - & - & - & - \\
\hline K8pf & $1.55 \pm 0.03$ & $60.32 \pm 0.06$ & $7.50 \pm 0.85$ & - & - & - & - & - & - \\
\hline K9pf & $3.21 \pm 0.02$ & - & - & $14.50 \pm 0.57$ & - & - & - & - & - \\
\hline K13pf & $2.72 \pm 0.06$ & - & $7.30 \pm 0.55$ & - & - & - & - & - & - \\
\hline K14pf & $1.92 \pm 0.03$ & - & $9.80 \pm 0.73$ & $15.40 \pm 0.50$ & - & - & - & - & - \\
\hline K18pf & $0.58 \pm 0.02$ & - & - & - & - & - & - & - & - \\
\hline K21pf & $0.56 \pm 0.01$ & - & $11.30 \pm 0.65$ & - & - & - & - & - & - \\
\hline K24pf & $7.86 \pm 0.01$ & - & $10.00 \pm 0.58$ & - & $15.00 \pm 0.58$ & - & - & - & - \\
\hline K25pf & $4.31 \pm 0.03$ & - & - & - & - & - & - & - & - \\
\hline K28pf & $2.60 \pm 0.01$ & - & - & - & - & - & - & - & - \\
\hline K29pf & $8.52 \pm 0.02$ & $72.41 \pm 0.01$ & $15.00 \pm 0.58$ & $20.30 \pm 0.87$ & $21.50 \pm 0.69$ & - & $12.00 \pm 0.98$ & - & + \\
\hline K32pf & $3.79 \pm 0.07$ & $91.86 \pm 0.03$ & $13.20 \pm 1.73$ & - & - & $13.70 \pm 0.64$ & $15.60 \pm 0.69$ & - & + \\
\hline K33pf & $6.52 \pm 0.02$ & $73.00 \pm 0.01$ & $12.50 \pm 0.98$ & - & $15.60 \pm 0.35$ & - & - & - & - \\
\hline K34pf & $3.18 \pm 0.04$ & - & - & - & - & - & - & - & - \\
\hline K35pf & $1.63 \pm 0.01$ & - & $8.90 \pm 0.65$ & - & - & - & - & - & - \\
\hline K37pf & $6.34 \pm 0.03$ & $75.66 \pm 0.01$ & $13.50 \pm 0.98$ & - & $10.30 \pm 0.35$ & - & - & - & - \\
\hline K38pf & $0.93 \pm 0.01$ & - & - & $10.00 \pm 0.49$ & - & - & - & - & - \\
\hline K41pf & $0.82 \pm 0.03$ & - & - & - & - & - & - & - & - \\
\hline K43pf & $2.45 \pm 0.12$ & - & $5.90 \pm 0.65$ & - & - & - & - & - & - \\
\hline K44pf & $1.75 \pm 0.08$ & - & - & - & $7.50 \pm 0.60$ & - & - & - & - \\
\hline K49pf & $0.98 \pm 0.06$ & - & $10.50 \pm 0.65$ & - & - & - & - & - & - \\
\hline K50pf & $2.53 \pm 0.03$ & - & $8.50 \pm 0.65$ & - & - & - & - & - & - \\
\hline$\underline{\mathrm{K} 51 \mathrm{pf}}$ & $3.25 \pm 0.05$ & - & - & - & - & - & - & - & - \\
\hline
\end{tabular}


tial isolates were identified based on their 16S rRNA sequence. The identity of the 5 isolates were tabulated in Table 4.

\section{Seed germination test}

Microbial benefit of seed germination can be an index of its potential benefit for agricultural, including propagation. Here, Pseudomonas sp. strain K29pf allowed a $90 \%$ germination of the seeds while Pseudomonas putida strain K33pf and Pseudomonas sp. K37pf had the lowest seeds germination rate of $70 \%$ (Table 5).

\section{Efficacy of Pseudomonas sp. strain K29pf on pot trial}

The mean temperature recorded of the glass house was $27^{\circ} \mathrm{C}$ during the morning and $34^{\circ} \mathrm{C}$ during the evening throughout the experiment. From all the test conducted, Pseudomonas sp. strain K29pf was chosen for the pot trial. It was observed that Treatment 3 gave the highest wet weight with the average wet weight of $75.6 \mathrm{~g}$ whereas Treatment 4 gave the lowest average wet weight of $28.5 \mathrm{~g}$ (Table 6). The observation on the root length indicated that Treatment 3 stimulate the longest roots elongation with the average of $13.1 \mathrm{~cm}$. The results also indicated that Treatment 2 stimulated the elongation of roots, however does not gave significant increase in the weight of Brassica chinensis var parachinens compared to Treatment 1 (Table 6).

\section{Discussion}

Indole-3-Acetic Acid which is an auxin, can stimulate cell elongation and division and also promote plant growth and development. However, high concentrations of IAA will cause toxicity to the plant such prevention of shoot and root growth. ${ }^{16}$ Study done by Rodrigues et al. ${ }^{17}$ indicated that $80 \%$ of the Pseudomonas sp. isolated from sugarcane showed the ability to produce IAA. In our study, all the 25 isolates of fluorescent pseudomonads isolated were observed to produce IAA. From this, we observed that

Table 4. Identification of selected fluorescent pseudomonads.

\begin{tabular}{llc} 
Isolate & Identity & $\begin{array}{c}\text { Similarity } \\
\text { (\%) }\end{array}$ \\
K24pf & Pseudomonas sp. & 99 \\
K29pf & Pseudomonas sp. & 99 \\
\hline K32pf & Pseudomonas aeruginosa & 99 \\
K33pf & Pseudomonas putida & 98 \\
\hline K37pf & Pseudomonas sp. & 99 \\
\hline
\end{tabular}

the highest IAA produced was only 8.52 $\mu \mathrm{g} / \mathrm{ml}$ which was considered low compared to IAA produced by Pseudomonas putida UB1 $(591.8 \mu \mathrm{g} / \mathrm{ml})$ is a study conducted by Bharucha et al. ${ }^{18}$ This observation indicated that the IAA reading obtained in this study were significantly low. However, study done by Dagnaw et al. ${ }^{19}$ stated that it is normal to obtained plant growth promoting rhizobacteria with low production of IAA due to the differences in species, strains and also the influence of different culturing condition.

Gibberellin acid is an endogenous hormone that function as plant growth regulators and influencing the developmental process of plants such as stem elongation, seed germination and sex expression. In this study, we observed that Pseudomonas aeruginosa strain $\mathrm{K} 32$ pf produced the highest $\mathrm{GA}_{3}(91 \mu \mathrm{g} / \mathrm{ml})$. This was higher compare to $\mathrm{GA}_{3}$ produced by Pseudomonas isolate $\mathrm{K} 8(70 \mu \mathrm{g} / \mathrm{ml})$ isolated by Desai. ${ }^{20}$ However comparison of $\mathrm{GA}_{3}$ production from Pseudomonas sp. done by Sharma et al., ${ }^{21} \mathrm{GA}_{3}$ production by Pseudomonas sp. isolated in this study were very low. Bottini et al. ${ }^{22}$ noted that production of $\mathrm{GA}_{3}$ might be influenced by factors such as the media used, the supply of $\mathrm{O}_{2}$ and $\mathrm{N}$.

In this study, Pseudomonas sp. isolate K29pf showed the most potential with the 15.0, 20.3 and $21.5 \mathrm{~mm}$ respectively of clear zones produced towards Ralstonia solanacearum, Erwinia caratovora and Erwinia mallotivora respectively. In a study conducted by Zhou et al., ${ }^{23}$ Pseudomonas brassicacearum $\mathrm{J} 12$ was observed to inhibit the growth of Ralstonia solanacearum. Pseudomonas putida ICCF 391 on the other hand showed antagonistic activity

against E. carotovora. ${ }^{24}$ Soare et al., ${ }^{24}$ mention that $E$. caratovora have the ability to produce bacteriocine, a compound that enable them to grow and inhibit other microbial growth. With the compound, $E$. carotovora can be seen as a microbes that are resistant to many other microbes. The formation of clear zone by only Pseudomonas sp. strain K29pf showed that this Pseudomonas sp. strain K29pf might have the ability to neutralize the bacteriocine produced by E. carotovora. ${ }^{24}$ Apart from producing antibacterial activity, Pseudomonas sp. strain K29pf also showed its ability to inhibit the growth of Colletotrichum gloeosporioides. These findings suggested that Pseudomonas sp. isolate K29pf has the potential to be develop into a beneficial biocontrol agent due to its effectiveness and board range of antimicrobial spectrum.

The ability of Pseudomonas sp. to fix nitrogen are considered to be rare. ${ }^{25}$ Indeed, in the study conducted by Lin et al. ${ }^{25}$ Pseudomonas stutzeri was the only known Pseudomonas sp. that fixed nitrogen. Unlike its rareness in fixing nitrogen, Pseudomonas sp. was well known for its ability to solubilize phosphate. In a study conducted by Dipak and Sankar, ${ }^{26}$ Pseudomonas sp. was noted as a good phosphate solubilizer and most Pseudomonas sp. have the ability to solubilize phosphate ${ }^{26-28}$ from the environment. However, in the present study we only isolated 2 pseudomonas

Table 5. Seed germination test of fluorescent pseudomonads.

\begin{tabular}{lc} 
Isolate & Percent of seed germinated \\
Pseudomonas sp. strain K24pf & $80.30^{*}$ \\
Pseudomonas sp. strain K29pf & $90.50^{*}$ \\
\hline Pseudomonas aeruginosa strain K32pf & $85.40^{*}$ \\
Pseudomonas putida strain K33pf & $70.80^{*}$ \\
\hline Pseudomonas sp. strain K37pf & $70.40^{*}$ \\
Control & $95.80^{*}$ \\
\hline *The mean value significantly differ according to Tukey's honest significant difference at $\mathrm{P}=0.05$ was showed.
\end{tabular}

Table 6. Plants dry weight, wet weight, dry weight percentage and root elongation vs treatments.

\begin{tabular}{lcccc} 
Treatment & \multicolumn{2}{c}{ Weight $(\mathrm{g})$} & Dry weight \% & Root elongation (cm) \\
& Fresh weight & Dry weight & & \\
+ +OF & $62.7^{*}$ & $12.5^{*}$ & 19.9 & $11.0^{*}$ \\
+ +PGPR & $54.8^{*}$ & $15.3^{*}$ & 27.9 & $11.5^{*}$ \\
\hline +OF+PGPR & $75.6^{*}$ & $21.5^{*}$ & 28.4 & $13.1^{*}$ \\
Control & $28.5^{*}$ & $5.4^{*}$ & 18.9 & $9.6^{*}$ \\
\hline
\end{tabular}

*The mean value significantly differ according to Tukey's honest significant difference at $\mathrm{P}=0.05$ was showed. 
with phosphate solubilizing properties. This could be due to the fact that fluorescent pseudomonads in this study were isolated form laterite soil which is well known for its low content of phosphorous.

A study by Tiwari and Singh ${ }^{29}$ indicated that Triticum aestivum (L) and Zea mays (L) seeds were inhibited by Pseudomonas aeruginosa. The infected seeds shown the character of soft and was covered by biofilm of the bacteria. However, in this study the seeds that did not germinate showed none of these attributes. However, Tabatabaei et al., ${ }^{30}$ stated that IAA levels, unknown metabolites produced by the bacteria and stress induced by the bacteria might also be one of the reason that seeds germination was inhibited.

Application of the potential microbes to the real world is away to test it functionality after completion of lab tests. From the study, +PGPR increased the weight of Brassica chinensis var parachinens but did not surpassed the wet weight of $+\mathrm{OF}$. This showed that by adding the Pseudomonas sp. alone, the microbes might not be able to provide the plants with the required nutrients from the soil for its growth. In $+\mathrm{OF}+\mathrm{PGPR}$, we saw an increased of $20 \%$ in the plant biomass compared to $+\mathrm{OF}$ only. This showed that combination of organic fertilizer and Pseudomonas sp. strain K29pf provide the plant with the needed nutrients and thus boosting the weight increment. This argument above is supported by finding from Antonius and Agustiyani, ${ }^{31}$ where they noted that application of beneficial microbes to the compost and application thereafter is the effective method to increase the biomass of the plants. Previous studies show that a biofertilizer prepared by combining PGPR with composts enhance growth-promoting effects and bio-control of the microbes towards the plants. ${ }^{32}$ Saia et $a l .{ }^{33}$ also observed that soil under fertilized condition with addition of PGPR increased the density of bacteria on the rhizoplane and also the $\mathrm{N}$ concentration of the plant.

\section{Conclusions}

Pseudomonas sp. are well known for their PGPR ability. In this study, Pseudomonas sp. K29pf isolated from kuini (Mangifera odorata) soil had showed its potential to produce phytohormones such as Indole-3-Acetic Acid and gibberellic acid, antimicrobial activities against Ralstonia solanacearum, Erwinia caratovora and Erwinia mallotivora and Colletotrichum gloeosporioides and also the ability to solubilize phosphate. This shows that Pseudomonas sp. K29pf can act as a good source of PGPR; further studies are needed to fully understand the efficacy of this bacteria on field.

\section{References}

1. Patten CL, Glick BR. Role of Pseudomonas putida indoleacetic acid in development of the host plant root system. Appl Environ Microbiol 2002;68:3795-801.

2. Mubarik NR, Mahagiani I, Anindyaputri A, et al. Chitinolytic bacteria isolated from chili rhizosphere: Chitinase characterization and its application as biocontrol for whitefly (Bemisia tabaci Genn.). Am J Agr Biol Sci 2010;5:430-5.

3. Bloemberg GV, Lugtenberg BJJ. Molecular basis of plant growth promotion and biocontrol by rhizobacteria. Curr Opinion Plant Biol 2011;4:343-50.

4. Wahyudi AT, Astuti RP, Widyawati A, et al. Characterization of Bacillus sp. strains isolated from rhizosphere of soybean plants for their use as potential plant growth for promoting Rhizobacteria. J Microbiol Antimicrobiol 2011;3:34-40.

5. Vasanthakumar A, McManus PS. Indole-3-acetic acid-producing bacteria are associated with cranberry stem gall. Phytopathology 2004;94:1164-71.

6. Pandya ND, Desai PV. Screening and characterization of GA3 producing Pseudomonas monteilii and its impact on plant growth promotion. Int J Curr Microbiol Appl Sci 2014;3:110-5.

7. Dey R, Pal KK, Bhatt DM, Chauhan SM. Growth promotion and yield enhancement of peanut (Arachis hypogaea L.) by application of plant growth-promoting rhizobacteria. Microbiol Res 2004;159:371-94.

8. King EO, Ward MK, Raney DE. Two simple media for the demonstration of pyocyanine and fluorescein. J Lab Clin Med 1945;44:301-7.

9. Iqbal A, Hasnain S. Auxin producing Pseudomonas strains: Biological candidates to modulate the growth of Triticum aestivum beneficially. Am J Plant Sci 2013;4:1693-700.

10. Wilson PW, Knight, SC. Experiments in bacterial physiology. Minneapolis, USA: Burguess; 1952. p 49.

11. Pikovskaya RI. Mobilization of phosphorus in soil in connection with the vital activity of some microbial species. Mikrobiologiya 1948;17:362-70.

12. Baniasadi F, Shahidi Bonjar GH, Baghizadeh A, et al. Biologial control of Sclerotinia sclerotiorum, causal agent of sunflower head and stem rot disease, by use of soil borne actinomycetes isolates. Am J Agr Biol Sci 2009;4:146-51.

13. Lee JY, Hwang BK. Diversity of antifungal actinomycetes in various vegetative soils of Korea. Canad J Microbiol 2002;48:407-17.

14. Jeffrey LSH. Isolation, characterization and identification of actinomycetes from agriculture soils at Semongok, Sarawak. Afr J Biotechnol 2008;7: 3700-5.

15. Weisburg WG, Barns SM, Pelletier DA, Lane DJ. 16 S ribosomal DNA amplification for phylogenetic study. J Bacteriol 1991;173:697-703.

16. Hansen H, Grossmann K. Auxininduced ethylene triggers abscisic acid biosynthesis and growth inhibition. Plant Physiol 2000;124:1437-48.

17. Rodrigues AA, Forzani MV, Soares RS, et al. Isolation and selection of plant growth-promoting bacteria associated with sugarcane. Pesquisa Agropecuária Tropical 2016;46:149-58.

18. Bharucha U, Patel K, Trivedi UB. Optimization of indole acetic acid production by Pseudomonas putida UB1 and its effects as plant growth-promoting rhizobacteria on Mustard (Brassica nigra). Agr Res 2013;2:215-21.

19. Dagnaw F. Characterization of plant growth promoting bacteria from sugarcane (Saccharum officinarum L.) rhizosphere of Wonji-Shoa Sugar Estate and farmers landraces of Ethiopia. Biotechnology 2015;14:58- 64 .

20. Desai SA. Isolation and characterization of gibberellic acid (GA3) producing rhizobacteria from sugarcane roots. Biosci Discov 2017;8:488-94.

21. Sharma S, Sharma A, Kaur M. Extraction and evaluation of gibberellic acid from Pseudomonas sp.: Plant growth promoting rhizobacteria. J Pharmacognosy Phytochem 2018;791: 2790-5.

22. Bottini R, Cassan F, Piccoli P. Gibberellin production by bacteria and its involvement in plant growth promotion and yield increase. Appl Microbiol Biotechnol 2004;65:497-503.

23. Zhou T, Chen D, Li C, et al. Isolation and characterization of Pseudomonas brassicacearum $\mathrm{J} 12$ as an antagonist against Ralstonia solanacearum and identification of its antimicrobial components. Microbiol Res 2012;167:388-94.

24. Soare MG, Caterina T, Maria P, et al. Antimicrobial activity of newly isolated Bacillus sp. and Pseudomonas sp. strains and their potential use as biocontrol agents. Scientific Bulletin. Series F. 
Biotechnol 2017;XXI.

25. Lin M, Yan Y, Lu W, et al. Regulatory coupling of nitrogen and carbon metabolism in nitrogen-fixing Pseudomonas stutzeri A1501. In de Bruijn FJ, ed. Biological Nitrogen Fixation. Hoboken, NJ, USA: John Wiley \& Sons, Inc; 2015.

26. Dipak P, Sankar NS. Isolation and characterization of phosphate solubilizing bacterium Pseudomonas aeruginosa KUPSB12 with antibacterial potential from river Ganga, India. Ann Agr Sci 2017;15:130-6.

27. Parani K, Saha BK. Prospects of using phosphate solubilizing pseudomonas as bio fertilizer. Eur J Biol Sci 2012;4:404.
28. Trivedi P, Sa T. Pseudomonas corrugate (NRRL B-30409) mutants increased phosphate solubilization, organic acid production and plant growth at lower temperatures. Curr Microbiol 2008;56: 140-4.

29. Tiwari P, Singh S. A plant growth promoting rhizospheric Pseudomonas aeruginosa strain inhibits seed germination in riticum aestivum (1) and Zea mays (L). Microbiol Res 2017;8:73-9.

30. Tabatabaei S, Ehsanzadeh P, Etesami H, et al. Indole-3-acetic acid (IAA) producing Pseudomonas isolates inhibit seed germination and a-amylase activity in durum wheat (Triticum turgidum L.). Spanish J Agr Res 2016;14:e0802.

31. Antonius S, Agustiyani D. Effects of biofertilizer containing microbial of $\mathrm{N}$ fixer, P-solibilizer and plant growth factor producer on cabbage (Brassica oleraceae var. capitate) growth and soil enzymatic activities: A greenhouse trial. J Biol Res 2011;16:149-53.

32. Chen LH, Tang XM, Raze W, et al. Trichoderma harzianum SQR-T037 rapidly degrades allelochemicals in rhizospheres continuously cropped cucumbers. Appl Microbiol Biotechnol 2011;89:1653-63.

33. Saia S, Rappa V, Ruisi P. Soil inoculation with symbiotic microorganisms promotes plant growth and nutrient expression in durum wheat. Front Plant Sci 2015;6:815. 